\title{
Pregnancies without Prenatal Care in the Health District of Commune V in Bamako: Obstetrical Prognosis
}

\section{Traoré Soumana Oumar ${ }^{1}$, Sylla Cheickna², Samaké Alou ${ }^{3}$, Doumbia Saleck ${ }^{1}$, Bocoum Amadou ${ }^{4}$, Fané Seydou${ }^{4}$, Sangaré Rokiatou Toriane1, Kéita Fatoumata1, Tégueté Ibrahima4, Traoré Youssour ${ }^{4}$, Mounkoro Niani ${ }^{4}$, Traoré Mamadou1, Dolo Amadou Ingré4}

\author{
${ }^{1}$ Healthcare Centre in Commune V, Bamako, Mali \\ ${ }^{2}$ Healthcare Centre in Koutiala, Koutiala, Mali \\ ${ }^{3}$ Healthcare Centre in Commune VI, Bamako, Mali \\ ${ }^{4}$ Gabriel Touré University Hospital Center, Bamako, Mali \\ Email: traoreoumar69@yahoo.fr
}

How to cite this paper: Oumar, T.S., Cheickna, S., Alou, S., Saleck, D., Amadou, B., Seydou, F., Toriane, S.R., Fatoumata, K., Ibrahima, T., Youssour, T., Niani, M., Mamadou, T. and Ingré, D.A. (2020) Pregnancies without Prenatal Care in the Health District of Commune V in Bamako: Obstetrical Prognosis. Open Journal of Obstetrics and Gynecology, 10, 1086-1092. https://doi.org/10.4236/ojog.2020.1080102

Received: June 20, 2020

Accepted: August 21, 2020

Published: August 24, 2020

Copyright () 2020 by author(s) and Scientific Research Publishing Inc. This work is licensed under the Creative Commons Attribution International License (CC BY 4.0).

http://creativecommons.org/licenses/by/4.0/ (c) (i) Open Access

\begin{abstract}
Summary: We attempted to determine the obstetric prognosis of women without antenatal care in the Health District of Commune V of Bamako, Mali. Materials and Methods: We undertook this retrospective case-control study from January 1 to March 31, 2017. Of all women having given birth to during this period in this district, we compared characteristics and obstetric outcomes between women without antenatal care (study group) vs. those with antenatal care (age/parity matched control). Results: $13.8 \%$ of women were without antenatal care (23.45 \pm 9.56 years of age: 13 - 42). Study group (without antenatal care), compared with control, was significantly more likely to be household helpers $(\mathrm{OR}=2.5[2.0-3.4])$ and single $(\mathrm{OR}=2.3[1.8$ $2.8]$ ). Study group women were more significantly likely to have the following poor obstetric outcomes: premature rupture of the membranes, post-maturity, low birth weight, hypertensive disorders of pregnancy, uterine rupture, fetal death, anemia, fetal malposition, cesarean section, postpartum hemorrhage, puerperal infection and maternal death. Study group showed a higher risk of early neonatal death, low Apgar score, and transfer to Neonatology institute. Conclusion: In accordance with the previous reports in any other countries, no prenatal checkup causes higher poor outcome of both mothers and infants/neonates also in this area.
\end{abstract}

\section{Keywords}

Absence of Prenatal Follow-Up, Obstetrical Prognosis 


\section{Introduction}

One of the targets of Sustainable Development Goal 3 is to reduce the global maternal mortality ratio to less than 70 per 100,000 live births and to reduce neonatal mortality to at least as low as 12 per 1000 live births [1]. Achieving this goal will depend in part on good prenatal care coverage. Prenatal care has been universally adopted as a medical practice that is organized around a set of simple but rigorous technical procedures leading to three essential objectives [2]:

$\checkmark$ Check the pregnancy and screen for all past and present risk factors;

$\checkmark$ Treat or refer the woman, when appropriate, for surveillance or specialized therapy for any risk factor identified;

$\checkmark$ Establish the prognosis of the childbirth, plan the conditions of childbirth in such a way that all practical measures are taken to avoid dangerous events as required.

Prenatal care is one of the four pillars of safe motherhood aimed at reducing maternal and perinatal morbidity and mortality [2] [3] [4].

The World Health Organization (WHO) recommends at least four prenatal care visits [5]. This number differs from country to country depending on each country's national recommendations. In DRC, Demographic and Health Surveys reported that the proportion of women who did not receive prenatal care was $20 \%$ in 2007 and 12\% in 2014 [6]. In Mali, according to DHS VI (2018) [7], 19\% of pregnant women had not received any prenatal care. Pregnancies without prenatal care are characterized by high maternal and fetal morbidity and mortality [8]. In Mali, there is a prenatal care component that includes health education to improve mothers' knowledge and attitudes about preventive care. The objective of this paper was to determine the obstetrical prognosis of pregnancies without prenatal care in the health district of the Commune V in Bamako.

\section{Materials and Methods}

The health district of Commune V is one of the six health districts of Bamako. Together with Commune VI, it constitutes the two health districts of Bamako located on the right bank of the Niger River. It includes thirteen community health centres (cscom) and one referral health centre (csréf) and many other private structures not included in this study. The study was cross-sectional, retrospective, analytical and case-control study that took place in the health district of Commune $\mathrm{V}$ in Bamako over a period of three months (3), from January 1 to March 31, 2017. The study included all women without prenatal care who gave birth in one of the fourteen (14) community and public structures of the health district of Commune V. This was a non-exhaustive sample with age and parity matching. The area of interest was the obstetric outcome (mother-fetus/newborn). The women were divided into two (2) groups. Group A was made up of women without prenatal care: these are the cases. Group B composed of women with prenatal care: these are the controls. In both cases, the gestational age was at least 28 weeks. We selected one (1) case for two (2) controls and matched age and parity. An individual investigation form developed 
for this purpose was filled out from obstetrical records and registers (birth records, referral/evacuation records of newborn patients, maternal deaths, stillbirths and neonatal deaths, hemorrhage, anesthesia, operative report, transfusion records). The achievement of prenatal care was considered a dependent variable and the independent variables were sociodemographic profile, labour data, maternal and perinatal prognosis. The data were entered in Word 2010 and Excel 2010 and analyzed by the Epi Info 7.2 software. The odds ratio (OR) was calculated and presented with its limits within the 95\% confidence interval (95\% $\mathrm{CI})$ and the significance level was set at $\mathrm{p}<0.05$. Administrative and communal approvals were prerequisites for this study.

\section{Results}

We recorded 5140 deliveries, of which 709 had not received prenatal care, resulting in a frequency of $13.8 \%$.

The mean age was $23.45 \pm 9.56$ years (for both groups of women) with extremes of 13 and 42 years (Tables 1-5).

Table 1. Socio-demographic profile of women.

\begin{tabular}{cccccccc}
\hline \multirow{2}{*}{ Profile } & \multicolumn{2}{c}{ Cases } & \multicolumn{2}{c}{ Controls } & & OR - IC \\
\cline { 2 - 5 } & $\mathrm{n}$ & $\%$ & $\mathrm{n}$ & $\%$ & & \\
\hline Domestic helps & 162 & 22.8 & 113 & 10.2 & & $10^{-9}$ & $2.5[2.0-3.4]$ \\
Singles & 275 & 38.8 & 236 & 21.4 & & $10^{-9}$ & $2.58[1.94-3.43]$ \\
Uneducated & 344 & 48.6 & 512 & 46.4 & & $10^{-9}$ & $1.1[0.9-1.3]$ \\
\hline
\end{tabular}

Table 2. Obstetric complications.

\begin{tabular}{|c|c|c|c|c|c|c|}
\hline \multirow{2}{*}{ Obstetric Complications } & \multicolumn{2}{|c|}{ Cases } & \multicolumn{2}{|c|}{ Controls } & \multirow{2}{*}{$\mathrm{p}$} & \multirow{2}{*}{ OR - IC } \\
\hline & $\mathrm{N}$ & $\%$ & $\mathrm{n}$ & $\%$ & & \\
\hline Evacuations & 294 & 41.5 & 267 & 14.2 & $10^{-9}$ & $2.2[1.8-2.7]$ \\
\hline Premature rupture of membranes & 243 & 34.3 & 88 & 79.9 & $10^{-9}$ & $2.3[1.9-2.9]$ \\
\hline Post maturity & 244 & 34.4 & 203 & 18.4 & $10^{-9}$ & $1.7[1.4-2.1]$ \\
\hline Low birth weight & 674 & 95.1 & 693 & 62.8 & $10^{-9}$ & $11.4[7.9-16.3]$ \\
\hline Hypertensive disorders & 85 & 12.0 & 36 & 3.3 & $10^{-9}$ & $4.0[2.7-6.0]$ \\
\hline Malposition & 142 & 20.0 & 158 & 14.3 & 0.001 & $1.5[1.2-1.9]$ \\
\hline Uterine rupture & 47 & 6.6 & 11 & 1.0 & $10^{-9}$ & $7.0[3.6-13.7]$ \\
\hline Fetal death & 142 & 20.0 & 158 & 14.3 & 0.001 & $1.5[1.2-1.9]$ \\
\hline Anemia & 108 & 15.2 & 22 & 2.0 & $10^{-9}$ & $8.8[5.5-14.12]$ \\
\hline IPPH & 34 & 4.8 & 12 & 1.0 & $10^{-7}$ & $4.6[2.4-8.9]$ \\
\hline Puerperal Infection & 65 & 9.2 & 9 & 0.8 & $10^{-9}$ & $12.3[6.1-24.8]$ \\
\hline
\end{tabular}

$\mathrm{IPPH}=$ immediate post-partum hemorrhage.

Table 3. Route of delivery and post-partum follow-ups.

\begin{tabular}{cccccccc}
\hline \multirow{2}{*}{ Route of delivery } & \multicolumn{3}{c}{ Cases } & \multicolumn{2}{c}{ Controls } & & \\
\cline { 2 - 5 } & $\mathrm{n}$ & $\%$ & $\mathrm{n}$ & $\%$ & & OR-IC \\
\hline Vaginal delivery & 278 & 69.5 & 612 & 76.5 & & 0.009 & $0.70[0.53-0.93]$ \\
\hline
\end{tabular}




\section{Continued}

\begin{tabular}{ccccccc}
\hline Abdominal delivery & 122 & 30.5 & 188 & 23.5 & 0.009 & $1.43[1.08-1.88]$ \\
IPPH & 34 & 4.8 & 12 & 1.0 & $10^{-7}$ & $4.6[2.4-8.9]$ \\
Puerperal Infection & 65 & 9.2 & 9 & 0.8 & $10^{-9}$ & $12.3[6.1-24.8]$ \\
\hline
\end{tabular}

Table 4. Maternal vital prognosis.

\begin{tabular}{|c|c|c|c|c|c|c|}
\hline \multirow{2}{*}{ Maternal vital prognosis- } & \multicolumn{2}{|c|}{ Cases } & \multicolumn{2}{|c|}{ Controls } & \multirow{2}{*}{$\mathrm{p}$} & \multirow{2}{*}{ OR-IC } \\
\hline & $\mathrm{n}$ & $\%$ & $\mathrm{n}$ & $\%$ & & \\
\hline Live & 705 & 99.4 & 1102 & 99.9 & - & - \\
\hline Deceased & 4 & 0.06 & 1 & 0.09 & \multirow{2}{*}{-} & \multirow[b]{2}{*}{-} \\
\hline Total & 400 & 100 & 800 & 100 & & \\
\hline
\end{tabular}

Table 5. The newborn's Apgar score at birth.

\begin{tabular}{|c|c|c|c|c|c|c|}
\hline \multirow{2}{*}{ 5-minute Apgar Scores } & \multicolumn{2}{|c|}{ Cases } & \multicolumn{2}{|c|}{ Controls } & \multirow{2}{*}{$\mathrm{p}$} & \multirow{2}{*}{ OR-IC } \\
\hline & $\mathrm{N}$ & $\%$ & $\mathrm{n}$ & $\%$ & & \\
\hline 0 & 81 & 11.1 & 80 & 6.9 & 0.002 & $1.7[1.2-2.23]$ \\
\hline$<8$ & 232 & 18.1 & 121 & 10.5 & $10^{-9}$ & $20.1[15.5-26.1]$ \\
\hline$\geq 8$ & 167 & 22.9 & 312 & 27.0 & 0.0008 & $0.8[0.6-1.0]$ \\
\hline Neonatology transfer & 167 & 22.9 & 203 & 17.6 & 0.05 & $1.4[1.1-1.8]$ \\
\hline
\end{tabular}

\section{Comments and Discussion}

During the study period, $13.8 \%$ of women had not received prenatal care. Disparate rates were reported across the literature. For example, Samaké A [9] reported a rate of $9.7 \%$ compared to $13.16 \%$ reported by Traoré Y [8] at Gabriel Touré University Hospital Center (CHU GT). According to the Demographic and Health Survey IV (Mali 2018) [10], 19\% of pregnant women had not received prenatal care. A pregnancy rate without prenatal care of $38 \%$ was reported in the Central African Republic and Kenya respectively [11] [12]. Much lower rates were reported in African studies: 10\% for El Hamdani in Marrakech, Morocco [13] and 7.35\% in Côte d'Ivoire [14]. Our population consisted of young women with an average age of $23.45 \pm 9.56$ years (for both groups of women) with extremes of 13 and 42 years. An average age of $24.01 \pm 6.30$ ( 15 and 43 years) was reported by Samaké A in Mali [9]. A recent study in Lubumbashi in the Democratic Republic of Congo (DRC) found that lack of prenatal care was associated with a statistically significant difference in the young age, unmarried and unemployed status of patients, and low educational attainment [15]. For Ndiaye [16], literacy associated with spousal refusal, risk unawareness, and unwanted pregnancies were additional factors in the absence of prenatal care. Ha BTT [17] concluded that educated women are better able to absorb messages about maternal health and therefore are more likely to attend prenatal care services.

Thus, among these women without prenatal care, we found a high rate of obstetrical evacuations, premature rupture of membranes, post-maturity, low birth 
weight, hypertensive disorders (pre-eclampsia and eclampsia), uterine rupture, fetal death, anemia, fetal malposition, cesarean delivery, immediate postpartum hemorrhage (IPPH), and puerperal infections. The consequences are maternal deaths, fetal deaths, newborn depression and neonatal deaths. Other authors in their publications have found similar results of complications in these women without prenatal care [9] [15]. In our work, the risk of premature rupture of membranes multiplied by 2.3 and the risk of low birth weight by 11.4 in women without prenatal care. Similar results have been reported in the literature [9] [15]. Women without prenatal care are prone to hypertensive disorders (eclampsia and pre-eclampsia) which can seriously affect maternal and fetal prognosis (with its corollary maternal death, fetal death, newborn depression and neonatal death). The risk of developing this serious condition was 4.0 times higher in women without prenatal care. During prenatal care, women benefit from iron + folic acid (IFA) supplementation, intermittent preventive treatment with sulfadoxine pyrimethamine (SP) and routine deworming. Maternal morbidity was dominated by uterine rupture, immediate postpartum hemorrhage, anemia and postpartum infection with a statistically significant difference for women without prenatal follow-up (OR-1). Maternity was characterized by malposition, uterine rupture, immediate postpartum hemorrhage and anemia, and puerperal infection with a statistically significant difference for women without prenatal care $(\mathrm{OR}>1)$. In our study, in women without prenatal care, the risk of Caesarean section increased by 1.43; the risk of uterine rupture by a factor of 7; the risk of immediate postpartum hemorrhage (IPPH) by a factor of 4.6; and the risk of puerperal infection by 12.3. We recorded five (5) maternal deaths of which four (4) were cases. Amani A [15] had noted 4.76 times more uterine ruptures in women who had not received prenatal care. Sepou A [18] in the Central African Republic and Traoré Y [8] in Mali all had the same result. Rasolonjatovo [18] found in his study that $92.2 \%$ of women admitted for uterine rupture had not attended prenatal care services

Lack of prenatal care seriously affects fetal well-being. The risk of fetal death was 1.5; it was 20.1 for depression (Apgar score $<8$ ) and 1.7 for early neonatal death. Our results are similar to those of many other authors [8] [9] [11] [15]. Poor Apgar score or depression in these newborns from mothers without prenatal care has been reported by many authors [8] [11] [15] [16]. Amani A [15] recovered a 2.70 -fold increase in risk of neonatal death. Samaké A [12] found a 3.14-fold increase in the risk of neonatal death. Traoré Y [8] reported a neonatal death rate of $10.9 \%$. In our study, among the survivors, $22.9 \%$ compared to 17.6\% were transferred to neonatology ( $\mathrm{OR}=1.4$ [1.1 - 1.8]). Amani A [15], reported $11.42 \%$ of neonates transferred to neonatology. The high transfer rate of newborns to neonatology among these women without prenatal care may be related to the many pathologies associated with these pregnancies (hypertensive disorders, anemia, genital infection) and which have not been managed, obstetric evacuation, delivery by caesarean section, malposition, uterine rupture, low birth weight, neonatal infection (premature rupture of membranes). 
The study limitations were those of a retrospective study, namely the lack of completeness of the data collected. This study did not examine certain aspects of prenatal consultation, namely the number, quality, qualification of the author, and location of consultations.

\section{Conclusion}

The rate of pregnancies without prenatal care remains high in the health district of Commune V in Bamako (Mali). The profile is that of an uneducated, unmarried domestic help. The evolution of these pregnancies is marked by numerous complications that strongly affect maternal and perinatal prognosis. Although the current data simply confirms the data from previous studies, we believe that each area should have its own data on this issue. The current data will be useful in developing health policy in this area.

\section{Authors' Contributions}

All authors participated in the drafting of the manuscript. They all approve the final version of the manuscript.

\section{Conflicts of Interest}

The authors declare that they have no conflict of interest in this paper.

\section{References}

[1] OMS (2019) Mortalité maternelle. 16 février 2018.

[2] Bhutta, Z., Darmstadt, G., Hasan, B. and Haws, R. (2005) Community-Based Interventions for Improving Perinatal and Neonatal Health Outcomes in Developing Countries: A Review of Evidence. Pediatrics, 115, 519-617. https://doi.org/10.1542/peds.2004-1441

[3] Bonono, R.C. and Ongolo-Zogo, P. (2012) Optimiser l'utilisation de la consultation prénatale au Cameroun. Centre pour le Développement des Bonnes Pratiques en Santé, Hôpital Central Yaoundé, Cameroun.

[4] Nkurunziza, M. (2014) Analyse du recours aux soins obstétricaux au Burundi: Déterminants et motivations. Presses universitaires de Louvain, Louvain.

[5] Villar, J., Ba'aqeel, H., Piaggio, G., Lumbiganon, P., Miguel Belizan, J., Farnot, U., et al. (2001) WHO Antenatal Care Randomised Trial for the Evaluation of a New Model of Routine Antenatal Care. The Lancet, 357, 1551-1564. https://doi.org/10.1016/S0140-6736(00)04722-X

[6] Ministère du Plan et Suivi de la Mise en oeuvre de la Révolution de la Modernité (MPSMRM), Ministère de la Santé Publique (MSP) and ICF International (2014) Enquête Démographique et de Santé en République Démocratique du Congo 2013-2014. MPSMRM, MSP et ICF International, Rockville, Maryland, USA.

[7] Bamako, Mali et Rockville, Maryland, Institut National de la Statistique (INSTAT), Cellule de Planification et de Statistique Secteur Santé-Développement Social et Promotion de la Famille (CPS/SS-DS-PF) and ICF (2019) Enquête Démographique et de Santé VI au Mali 2018.

[8] Traore, Y., Teguete, I., Thera, A.T., Mulbah, J.K., Mounkoro, N., Diarra, I., et al. 
(2007) Aspects Socio-Démographiques et pronostic des grossesses non suivies chez les patientes admises dans le service de Gynécologie-Obstétrique de l'hôpital Gabriel Touré. Mali Medical, 22, 39-43.

[9] Samakè, A., Traoré, S.O., Kéita, M., Albachar, H., Traoré, O.M., Diallo, M., et al. (2020) Grossesses non suivies: Pronostic maternel et périnatal au Centre de Santé de Référence de la Commune V du District de Bamako. Health Sciences and Diseases, 21, 74-77.

[10] Sepou, A., Yanza, M.C., Nguembi, E., Bangamingo, J.P. and Nali, M.N. (2000) Les consultations prénatales en zone Semi-Urbaine centrafricaine: Fréquence, facteurs influençant, pronostic maternel et néonatal. Médecine Tropicale, 60, 257-261.

[11] Brown, C.A., Sohani, S.B., Khan, K., Lilford, R. and Mukhwana, W. (2008) Antenatal Care and Perinatal Outcomes in Kwale District, Kenya. BMC Pregnancy and Childbirth, 8, Article No. 2. https://doi.org/10.1186/1471-2393-8-2

[12] El Hamdani, F.Z., Vimard, P., Baali, A., Zouini, M. and Cherkaoui, M. (2013) Soins prénatals dans la ville de Marrakech. Médecine et Santé Tropicales, 23, 162-167. https://doi.org/10.1684/mst.2013.0185

[13] Mian, D.B., Koffi, S., Oko, R., Kouakou, F., Nguessan, K.L.P., Abauleth, Y.R. and Boni, S. (2014) Early Neonatal Issues of Under-Followed Pregnancies at the Maternity Hospital of Cocody-Abidjan. RAMUR Tome, 19, 2.

[14] Maleya, A., Kakudji, Y.K., Mwazaz, R.M., Nsambi, J.B., Ngwej, H.I., Mukuku, O., Kinenkinda, X. and Luhete, P.K. (2019) Issues Materno-Fœtales des grossesses non suivies à Lubumbashi, République Démocratique du Congo. The Pan African Medical Journal, 33, 66. https://doi.org/10.11604/pamj.2019.33.66.18528

[15] Ndiaye, P., Tal Dia, A., Diediou, A., Dieye, E.H.L. and Dione, D.A. (2005) Déterminants socioculturels du retard de la première consultation prénatale dans un district sanitaire au Sénégal. Santé Publique, 1, 531-538. https://doi.org/10.3917/spub.054.0531

[16] Ha, B.T.T., Tac, P.V., Duc, D.M., Duong, D.T.T. and Thi, L.M. (2015) Factors Associated with Four or More Antenatal Care Services among Pregnant Women: A Cross-Sectional Survey in Eight South Central Coast Provinces of Vietnam. International Journal of Women's Health, 7, 699-706. https://doi.org/10.2147/IJWH.S87276

[17] Sepou, A., Yanza, M.C., Nguembi, E., Bangamingo, J.P. and Nali, M.N. (2000) Les consultations prénatales en zone Semi-Urbaine centrafricaine: Fréquence, facteurs influençant, pronostic maternel et néonatal. Médecine Tropicale, 60, 257-261.

[18] Rasolonjatovo, J.D.C., Randaoharison, P.G., Randrianirina, J.B.S., Randrianarison, P. and Rassolofondraibe, A. (2005) Prévalence des ruptures utérines à Antsirabe (Madagascar). Médecine d' Afrique Noire, 52, 525-528. 